\title{
Towards ecosystem for research and development of electrodermal activity applications
}

\author{
Jari Jussila ${ }^{\dagger}$ \\ Häme University of Applied \\ Sciences \\ Finland \\ jari.jussila@hamk.fi \\ Jarkko Moilanen \\ Ministry of Education and Culture \\ P.O. Box 29 \\ Finland \\ jarkko.moilanen@minedu.fi
}

\author{
Niina Venho \\ Vigofere Oy \\ Tampere \\ Finland \\ niina.venho@vigofere.com \\ Jari Liukkonen \\ Finnpos Systems Oy \\ Tampere \\ Finland \\ jaliukko@gmail.com
}

\author{
Henna Salonius \\ Vigofere Oy \\ Tampere \\ Finland \\ henna.salonius@vigofere.com \\ Mikael Rinnetmäki
Sensotrend Oy
Tampere
Finland
mikael@sensotrend.com
}

\begin{abstract}
Electrodermal activity is one of the most studied psychophysiological markers of the functioning of the autonomic nervous system and it has been applied in psychophysiological research for over 100 years. However, electrodermal activity measurement has not been largely applied in clinical research until now due to it being limited to laboratory environment before the entry of wearable devices. The aim of this study is to speed up research and development of electrodermal activity applications based on wearable device measurements. In order to reach that goal an ecosystem model is proposed that includes open data, open source, application programming interface and software development kit as central components. To illustrate the ecosystem model a case study of Moodmetric is presented.
\end{abstract}

\section{CCS CONCEPTS}

- Computing methodologies $\rightarrow$ Machine learning; Machine learning approaches; - Information systems $\rightarrow$ Information systems applications $\rightarrow$ Decision support systems $\rightarrow$ Data analytics

\section{KEYWORDS}

Electrodermal activity, galvanic skin response, skin conductance, wearables, open data, open source, application programming interface, ecosystem

\footnotetext{
Permission to make digital or hard copies of part or all of this work for personal or classroom use is granted without fee provided that copies are not made or distributed for profit or commercial advantage and that copies bear this notice and the full citation on the first page. Copyrights for third-party components of this work must be honored. For all other uses, contact the Owner/Author

Mindtrek 2018, October 10-11, 2018, Tampere, Finland

CC 2018 Copyright is held by the owner/author(s) ACM ISBN 978-1-4503-6589-5/18/10. https://doi.org/10.1145/3275116.3275141
}

\section{Introduction}

Electrodermal activity (EDA) is one of the most studied psychophysiological markers of the functioning of the autonomic nervous system and it has been applied in psychophysiological research for over 100 years [6]. However, due to lack of wearable devices that can be worn comfortably during normal daily life and over extensive periods of time EDA measurement has been limited to laboratory settings [31] and has not been largely applied in clinical research. Recently wearable EDA devices have become available, which make EDA measurement appealing for both psychological research and clinical use [8]. Wearable EDA devices have been introduced in many shapes and forms, including rings [35, 39], gloves [26], wristbands [16], smartwatches [30], and socks [23]. In psychological research, wearable sensors allow experiments to take place in more ecologically valid settings [2], while in health care wearable sensors enable continuous physiological monitoring at a relatively low cost $[8,29]$.

The aim of this study is to speed up research and development of electrodermal activity applications based on wearable device measurements. In order to reach that goal an ecosystem model is proposed that includes open data, open source, application programming interface (API) and software development kit (SDK) as central components. In this study the term ecosystem is used to refer to a network of interconnected organizations that are linked to or operate around a focal firm or a platform [20,28], the platform in this case referring to the Moodmetric platform (Figure $1)$.

In management research the difference between ecosystem and other network constructs has been defined in manner that ecosystem covers both production side and use side participants, including complementary asset providers and customers [38]. 
Application programming interfaces (APIs) have a central role in ecosystems, as they provide the means to connect to platforms and to monetize data and services from the perspective of the platform owner $[10,41]$. In the simplest terms, APIs are specifications that govern interoperability between applications and services [41]. In global economy APIs have risen as a significant approach for developing applications, building ecosystems and participating in the platform economy [27].

Platforms often contain technical boundary resources also known as APIs for other ecosystem participants [3]. Central role of APIs in service development and platform development have in turn created phenomenon known as API Economy.

In API Economy company utilizes resources efficiently and quickly to create added value for own customers. These resources can be for example data or function provided by other organizations. Building blocks utilized are own APIs and public APIs provided by other organizations (free or commercial) in addition to developer communities. These enable quicker adaptability to unpredictable and faster changing customer needs. Defining characteristics of API Economy are competing for popularity among application developers and considering them as primary customers. In brief, services are offered from businesses to developers (Business-to-Developers, B2D). [27]

It has been even claimed that 'we are in the midst of a reorganization of our economy in which the platform owners are seemingly developing power that may be even more formidable than was that of the factory owners in the early industrial revolution.' [24]

\section{Electrodermal activity}

Electrodermal activity is an indicator of the sympathetic activity of the autonomic nervous system that is associated with emotion, cognition, and affection [9], and has been found as a relevant indicator of stress level of a person [23, 34]. EDA can be measured through changes in electrical conductance of the skin [40]. Eccrine sweat glands activate as a response to the unconscious actions of the human body regulated by the autonomic nervous system. The sweat glands are exclusively innervated by the sympathetic nervous system [6], which makes skin conductance an ideal measure for sympathetic activation in contrast to other physiological measures (e.g. the heart rate) that are influenced by both the sympathetic and the parasympathetic nervous systems [34]. Eccrine sweat glands' density is high at palms of hands, which makes a ring form ideal to measure EDA [29].

Diseases relating to the functionality of the autonomic nervous system may affect electrodermal activity. Patients with hyper- or hypothyroidism have been recorded with unusual EDA measurements $[11,12]$. Within a variety of anxiety disorders (e.g. panic disorder and posttraumatic stress disorder), increased electrodermal activity and reactivity has been observed $[5,7,19$,
25]. However, in depression electrodermal activity is often reduced $[1,42]$.

\section{Ecosystem model for research and development of wearable applications}

An ecosystem model for research and development of wearable applications is outlined (Figure 1). Consumers are at the top of the ecosystem and can include e.g. individual consumers that own a wearable, researchers that use the wearables to conduct measurements, and corporate users that either own a wearable or have leased a wearable for duration of a measurement period (for instance from occupational health care service providers). The data from the wearables is stored to Application(s), which can be e.g. native iOS and Android applications or progressive web applications [4]. From the Application(s) data is sent to cloud platform that can ingest and integrate data from several wearables. The cloud platform further provides a Partner API that individuals, researchers and corporate users can use to access the data and build new applications.

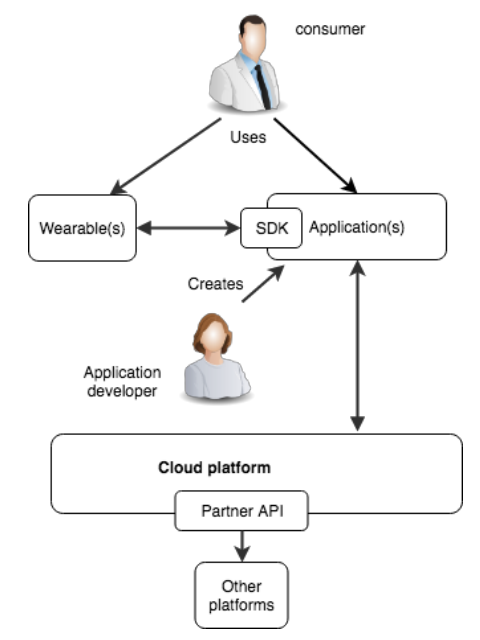

Figure 1: Ecosystem model for research and development of wearable applications

Moodmetric is illustrated as an instance of this proposed ecosystem model and described in more detail in the case study. In the Moodmetric ecosystem, different wearable vendors provide devices for consumers. Application developers create new applications with the provided SDK and applications are distributed via Google Play, Apple App Store and developer websites. Wearable(s) vendors in the ecosystem currently include Moodmetric and Kalevala Jewelry. Application(s) include Moodmetric (iOS and Android) app and Förger Analytics FSenSync software package for synchronized recording and streaming of sensor data [15], for example. Moodmetric cloud functions as the cloud platform that receives data from the Moodmetric app. 
Towards ecosystem for research and development of electrodermal activity applications

The Moodmetric API allows to access the Moodmetric cloud platform data. This makes it possible to build other platforms and applications using the Moodmetric data. For instance, an elderly care home could observe stress levels of residents via their own platform that requests the Moodmetric data from the Moodmetric cloud. Viewed more broadly the Moodmetric platform could be part of a health and wellness ecosystem. Ideally this kind of ecosystem would be one or several platforms with unlimited amount of data providers. Data providers would have open API to access their data. On the platform this data could be combined to other data providers' data or data from any ecosystem partner.

In summary, the ecosystem could include the following ecosystem roles: consumers, data providers, application developers, data users, wearable device vendors and platform owner [see 27]. Data provider could be any public or private company or even an individual with data that could be of interest for data users in this ecosystem. Data users could in this ecosystem be researchers, universities, hospitals, medical companies, pharmaceutical companies, private medical centers, care homes etc. They could access data on the platform with commonly set rules and limitations.

\section{Case study of the Moodmetric smart ring}

The case study was chosen as a research method for this research. Case study method was considered as appropriate, because it allows empirical investigation of contemporary phenomenon within its real life context using multiple sources of evidence [43]. The study employs a descriptive case study method to what might be considered as a typical case [44] of a start-up company aiming to build an ecosystem utilizing its platform and services. The aim of the case study is to describe the start-up company, its platform and services, and how the company attempts to build an ecosystem for research and development of EDA applications.

The Moodmetric smart ring for preventive stress management is an invention of a Finnish company Vigofere Oy. The inventor Henry Rimminen (Ph.D.) came up with the idea of incorporating the EDA measurement into a ring in 2011. The Moodmetric smart ring is a bio-sensor measuring EDA from the palmar side of the wearer's hand. Palmar side of the hands or the feet are typically used for EDA measurement, because that is where the density of sweat glands is the highest $(>2000 / \mathrm{cm} 2)$ [34]. The measurement signal accuracy of the Moodmetric smart ring is comparable to laboratory devices and the research conducted by the Finnish Institute of Occupational Health [39] has found the device valid for field research. The ring transfers the EDA reading from the ring's memory to a mobile application by Bluetooth and via the application also to cloud if the user has enabled cloud synchronization. Due to internal memory of the ring, the user is not constrained to stay close to the mobile device. The ring acts both as a data forwarding and data logging device, which enables unrestricted continuous measurement regardless of location and distance to the mobile device. Real-time viewing of the
Mindtrek 2018, October 10-11, 2018, Tampere, Finland

measurement data on the mobile app is, however, possible within the Bluetooth range, $\sim 5 \mathrm{~m}$ of the mobile device.

Vigofere Oy has developed an algorithm that describes arousal of a person on a scale of 0 to 100 , called the Moodmetric (MM) index or the Moodmetric level. When the index numbers are high, the sympathetic nervous system is very active. High arousal can be both positive and negative. When the index numbers are low, the parasympathetic nervous system is working, and the body is recovering. The in-built algorithm learns from the user and gives 100 to the highest experienced load and 0 to lowest. The MM level 100 means being extremely stressed, excited, anxious or frightened. At about 50 the mind is active while below 30 means being relaxed. Level 1 can be reached at deep sleep. The Moodmetric index daily average number is assumed to be an indicator of the balance of the autonomic nervous system (see Figure 2). This balance is especially important when the target is to prevent chronic stress.

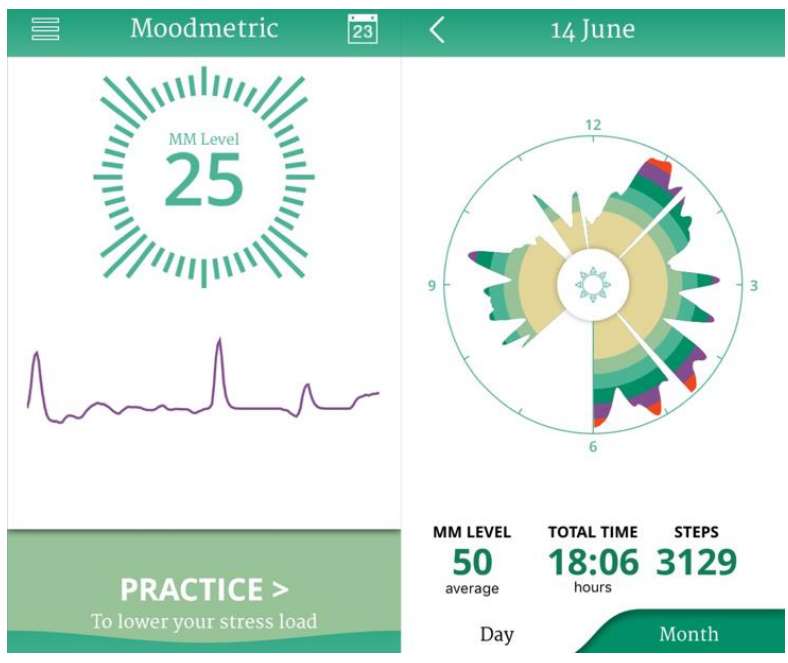

Figure 2: Moodmetric mobile application screen capture of default view and day view.

The default application view on the left side of Figure 2 displays the raw signal and MM the index, and the day view on the right describes the daily average number of the MM index, the total time measured during the 24 hours and step count of the day. In Figure 2, at the bottom of the left side is the Practice feature. The Practice can be used to track calmness or arousal during a pre-set time. The MM index / time chart is drawn and can be viewed in real-time, and the details separately logged after the exercise. (see Figure 3 for details). 


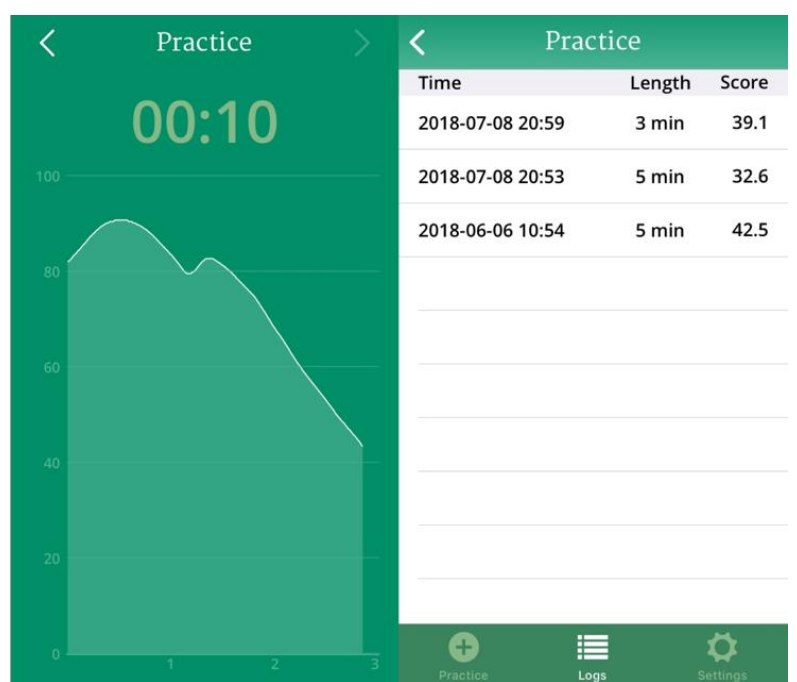

Figure 3: Practice mode and Practice log.

With Moodmetric measurement it is possible to understand the calming effect of any user preferred exercise. In practice mode the user can choose a duration of 1-60 minutes time to practice and get feedback from the exercise, e.g. breathing or a mindfulness exercise $[13,17,22]$, to find the most soothing music by measuring the effect, or to record the calming effect of nature by spending a moment in the woods $[18,32,33]$. The practice can be performed silently. Or the user can choose water waves, or clock as a background sound. Also, external audio can be used, to support best relaxation during the exercise. Each practice session is recorded, and the user can thus observe the development in the exercises and their impact to the autonomic nervous system. For each practice session, the time of the session, the length of the session, as well as the average MM level score is recorded (Figure $3)$.

The Diary feature provides the user the possibility to follow MM levels of activities in calendar form. The activities can be categorized to better understand how e.g. work or family affect the MM level. Activities can be added to the Moodmetric mobile app manually or uploaded from the phone calendar. As the EDA measurement is unable to make a distinction between positive or negative mood, the diary function enables to log activities and add to the measured arousal the mood during particular activity (see Figure 4). By doing so, the user can keep track, which activities cause high or low arousal and positive or negative valence, as outlined by Cowley et al. [8].

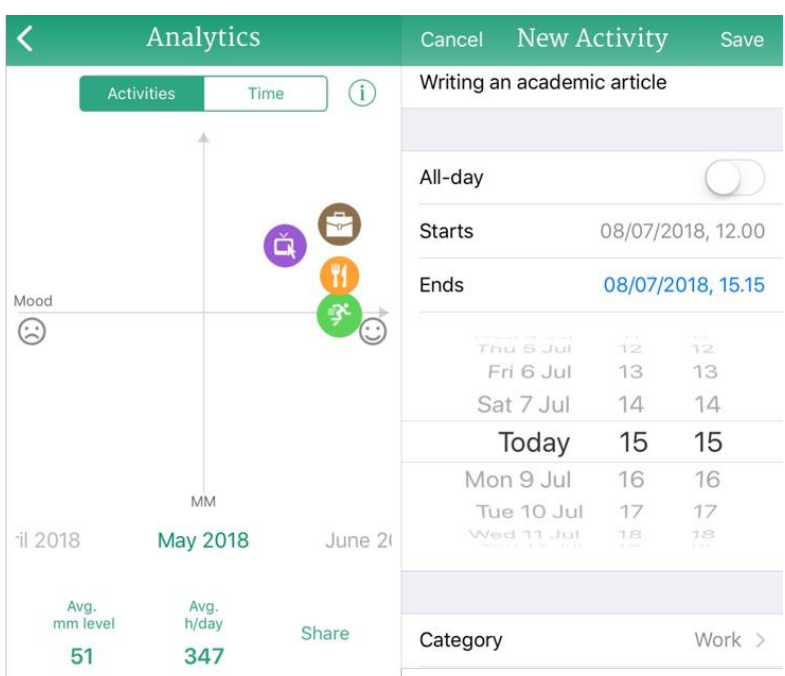

Figure 4: Analytics of user activities and diary for reporting the activities.

In addition to the mobile application, Moodmetric data can be viewed and accessed from Moodmetric cloud platform. The Moodmetric cloud service includes a dashboard, where day, night and weekly chart of measurements are visualized, and statistics of MM levels are provided (Figure 5).

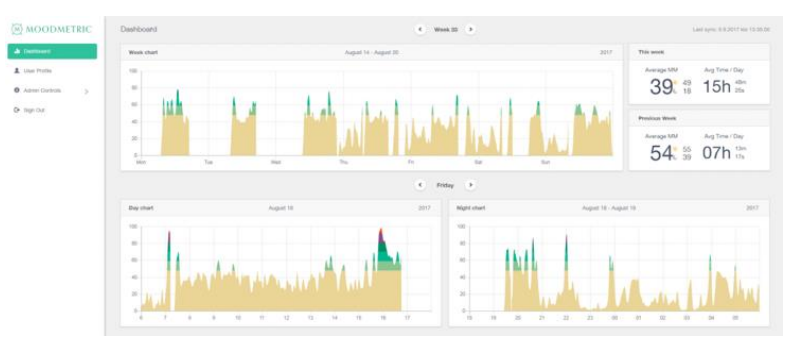

Figure 5: Moodmetric cloud service dashboard.

The users can synchronize data from several smart rings to the cloud platform, and also export the data as CSV-file from the platform. The platform includes also a service for group monitoring, e.g. for monitoring the stress of teams or other organizational units. The platform provides also APIs for accessing the data and enabling to build third-party services.

One motivation for providing open data, software development kits, and application programming interfaces were recognized by the company, while participating in hackathon events [37], e.g. DigiSyke Health Hack, Hyvinvointihackathon (Wellness hackathon), SAPSyke Hackathon, and BHTC Hackathon, where the goal was that anyone could develop new services and applications that make use of the Moodmetric smart rings. Typically, the requirement in such cases are that open data and API's are available for the participants. 
Towards ecosystem for research and development of electrodermal activity applications

\section{Open data of electrodermal activity measurements}

In the case of the Moodmetric smart ring, the data can be accessed via the cloud or exported from the mobile device. Example of data collected with the Moodmetric smart ring is available from GitHub: https://github.com/KariSuoja/MoodmetricDataViz/data.

Data exported directly from the smart ring contains three tables: datalog (see Figure 2), relaxlog (see Figure 3) and diarylog (see Figure 4). Datalog contains the most essential measurement data and is also synchronized to cloud, whereas the two other logs are by default stored only to the mobile device. A description of the datalog is illustrated on Table 1 .

Table 1: Moodmetric smart ring datalog.

\begin{tabular}{|c|c|c|}
\hline $\begin{array}{l}\text { Column } \\
\text { number }\end{array}$ & Variable & Description \\
\hline 1 & user_id & $\begin{array}{l}\text { Identification number for the } \\
\text { user. }\end{array}$ \\
\hline 2 & ring_id & $\begin{array}{l}\text { Identification number for the } \\
\text { smart ring. }\end{array}$ \\
\hline 3 & time & $\begin{array}{l}\text { Time in milliseconds starting } \\
\text { from the date 1.1.1970. }\end{array}$ \\
\hline 4 & scrn & $\begin{array}{l}\text { Activations per minute / skin } \\
\text { reactions per minute. This integer } \\
\text { typically variates between } 0 . .20 \\
\text { with a typical rate of } \sim 3-4 \text {. }\end{array}$ \\
\hline 5 & $\mathrm{~mm}$ & MM index. \\
\hline 6 & $\mathrm{scl}$ & $\begin{array}{l}\text { Raw level of conductance of the } \\
\text { skin. The unit is micro siemens } \\
(\mu \mathrm{S}) \text { and the value typically } \\
\text { varies between } 0.2-20 \mu \mathrm{S} \text {. }\end{array}$ \\
\hline 7 & steps & Number of steps. \\
\hline 8 & aa & User calibration value. \\
\hline 9 & synced & $\begin{array}{l}\text { Syncing to cloud: } 1=\text { synced, } 0= \\
\text { not synced). }\end{array}$ \\
\hline
\end{tabular}

From the cloud the datalog can be also downloaded as a CSV-file. The CSV-file is nearly identical with the datalog table presented in Table 1, however, the synchronization information is only stored in the mobile device and CSV export from cloud contains device_id as additional variable.

The relaxlog is illustrated on Table 2 and diarylog on Table 3 . The relaxlog contains the data visualized in Figure 3, with additional variables identifying the user and the smart ring used.
Mindtrek 2018, October 10-11, 2018, Tampere, Finland

Table 2: Moodmetric smart ring relaxlog.

\begin{tabular}{|c|c|c|}
\hline $\begin{array}{l}\text { Column } \\
\text { number }\end{array}$ & Variable & Description \\
\hline 1 & user_id & Identification number for the user \\
\hline 2 & ring_id & $\begin{array}{l}\text { Identification number for the } \\
\text { smart ring }\end{array}$ \\
\hline 3 & length & Length of the practice session \\
\hline 4 & score & Average MM index of session \\
\hline 5 & synced & $\begin{array}{l}\text { Syncing to cloud: } 1=\text { synced, } 0= \\
\text { not synced) }\end{array}$ \\
\hline 6 & name & $\begin{array}{l}\text { Name given to the practice } \\
\text { session (optional) }\end{array}$ \\
\hline
\end{tabular}

Diarylog contains data on both the measured and user logged events. When a user inputs the time interval of the activity (see Figure 4), the diarylog stores the start and end time as separate values that are used to compute the average MM index (stored in datalog) for the activity. Similarly, diarylog contains the practiceId value that connects it to practice events (stored in relaxlog). Description of all the diarylog variables are illustrated on Table 3.

Table 3: Moodmetric smart ring diarylog.

\begin{tabular}{|l|l|l|}
\hline $\begin{array}{l}\text { Column } \\
\text { number }\end{array}$ & Variable & Description \\
\hline 1 & title & Name given to activity \\
\hline 2 & category & Activity category. \\
\hline 3 & mood & $\begin{array}{l}\text { Mood during activity on } \\
\text { unhappy-neutral-happy scale. }\end{array}$ \\
\hline 4 & start & Start time of the activity. \\
\hline 5 & end & End time of the activity. \\
\hline 6 & all_day & All-day long activity. \\
\hline 7 & notes & $\begin{array}{l}\text { Text field for documenting notes } \\
\text { about the activity. }\end{array}$ \\
\hline 8 & tag & User given tag to the activity. \\
\hline 9 & calld & $\begin{array}{l}\text { Identification number } \\
\text { calendar events }\end{array}$ \\
\hline 10 & practiceld & $\begin{array}{l}\text { Identification number for the } \\
\text { practice session }\end{array}$ \\
\hline 11 & synced & $\begin{array}{l}\text { Syncing to cloud: 1= synced, 0= } \\
\text { not synced). }\end{array}$ \\
\hline
\end{tabular}

The categories available for activities include: Sport, Work, Family, Relax, TV / Web, Dining, Art, Travel, Sleep, Other. In addition to the predefined categories, the user can give his/her own category as tag. Both Table 2 and Table 3 contain a column called synced, however, this data is not currently synced to cloud due to restricting potentially sensitive data being transferred to cloud. This is to avoid scenarios, where such data might be leaked out or combined to other data in a way that compromises privacy or security of the users $[21,36]$. 


\section{Open source application for visualization of electrodermal activity data}

An open source application called MoodmetricDataViz has been developed for visualization of electrodermal activity data that works with the open data described in previous chapter. An earlier release [35] was updated to include support for (database exports from) Android devices, and visualizations for extended time periods (from 24 hours to one week). The purpose of the open source solution is to offer a complementary tool for those researchers that are familiar with $\mathrm{R}$ and wish to develop their own solutions from data extracted from mobile devices. Alternatively, developers and researchers can use the previously described cloud service or API described in next chapter.

The application takes database files downloaded from the mobile devices to a PC/Mac folder as input data for the tool. The data collection approach in this instance is simply downloading the database files from the mobile device to the input folder of the $\mathrm{R}$ application. The user needs, in minimum, to download and install $\mathrm{R}$ free software environment to be able to use the application. The application loops through all the stored database files in the input folder, pre-processes the content, computes additional data values based on the measurement data and generates easily understandable visualization from the data. The output files are written in separate folder where there is one summary Excel workbook for all given measurement data and dedicated Excel workbooks for each database input files. The data in the workbooks are separated to worksheets based on the content, figures have their own worksheet, graphs their own and each of the actual numeric information is in their own sheet.

The measurement data contains typically breaks due to various human reasons (people take the ring off the finger for a short period of time for going to swim, etc.), which need to be taken into account in data processing. The tool also adds in the worksheets the length of the actual sample data i.e. the total amount of sample minutes (breaks taken into account).

Data outputs include a trend curve, a Circle diagram and the data in spreadsheet format for the selected processing period. The trend curve is produced for each user (database file) to visualize the Moodmetric MM level value variation during the selected time period. Trend curve is filled with colors from red to beige to emphasize the MM level (Figure 6).

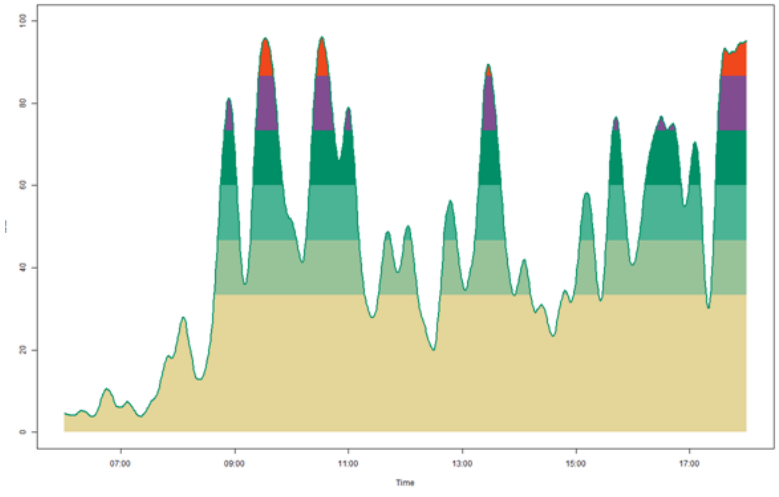

Figure 6: Trend curve from the open data.

The second data visualization produces the circle diagram (Figure 7), which follows the same principles as the mobile application in presenting Moodmetric MM level as twelve hours sets. One set is for daytime i.e. from 6:00 to 18:00 and another for nighttime i.e. from 18:00 to 6:00. The data processing tool creates as many twelve-hour diagrams as needed to cover the given time period. Color coding for circle diagram is identical to the coding on trend curves (Figure 6).

The application converts the MM value data to polar coordinate values for plotting the circle diagram, each of the twelve-hour sets representing a full circle. Polar co-ordinate values are calculated separately for each color coding zones taking in account of the maximum value of each zone. The application produces the circle diagram by plotting the calculated polar coordinate values as polygons starting from the highest color coding zone.

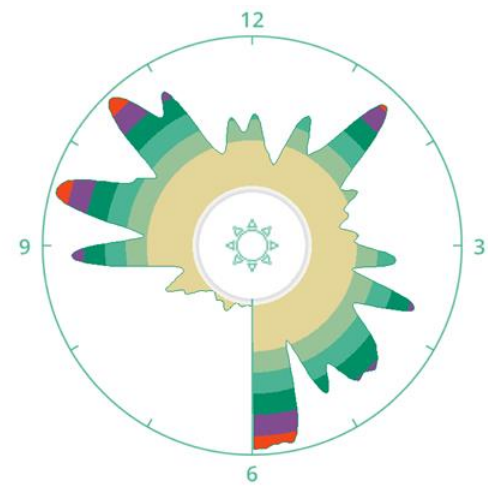

Figure 7: Circle diagram of the open data.

Finally, the application provides the MM value data used for trend curve and the circle diagram also in numeric format for further processing and analysis (Table 4). 
Towards ecosystem for research and development of electrodermal activity applications

Table 4: Open source data in table form.

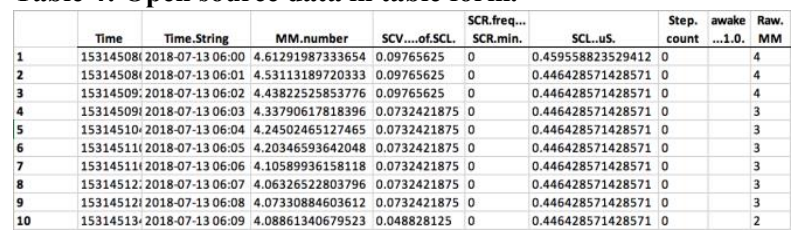

In addition to the MM values the Excel work sheet for numeric values includes: time stamp, activations per minute / skin reactions per minute (SCR frequency per minute), $\%$ of SCL value (SCV value), raw level of conductance of the skin (SCL), step count, MM value, and awake/sleep indicator (feature currently not active in the application) as illustrated in Table 4.

\section{$7 \quad$ API and SDK for developing research tools and third-party applications}

The Moodmetric API makes it possible to benefit from data at the Moodmetric cloud. The Moodmetric API is a partner API type and available upon request and is shared with companies building e.g. health and wellness data platforms. The aim is to increase use and awareness of the EDA signal by providing an open API to all requestors with appropriate solutions. Via the Moodmetric API it is possible to access, for example, the indexed measurement data.

The Moodmetric SDK is intended for external app developers and also available free of charge. It includes full documentation of the interface and also example applications for iOS and Android. Example of features provided by the SDK include:

- The MM number notification tells if the person is very stressed or excited. High MM notification is issued when the MM level is elevated for over 5 minutes.

- The Relax notification tells if the person has successfully managed to relax for example in a meditation exercise. Relax notification is issued when the MM level is low for over 5 minutes.

- The strong reaction notification tells if a strong emotional reaction has been detected at a certain moment, for example, when testing responses to images and sounds.

\section{Discussion and conclusions}

Successful platforms of the future provide valid, interesting and timely data. They enable easy access and possibility to combine external data. Open interfaces and SDKs provide a way to have data easily available on one or several platforms. Based on the case study, a vision future of the Moodmetric platform is illustrated in Figure 8.
Mindtrek 2018, October 10-11, 2018, Tampere, Finland

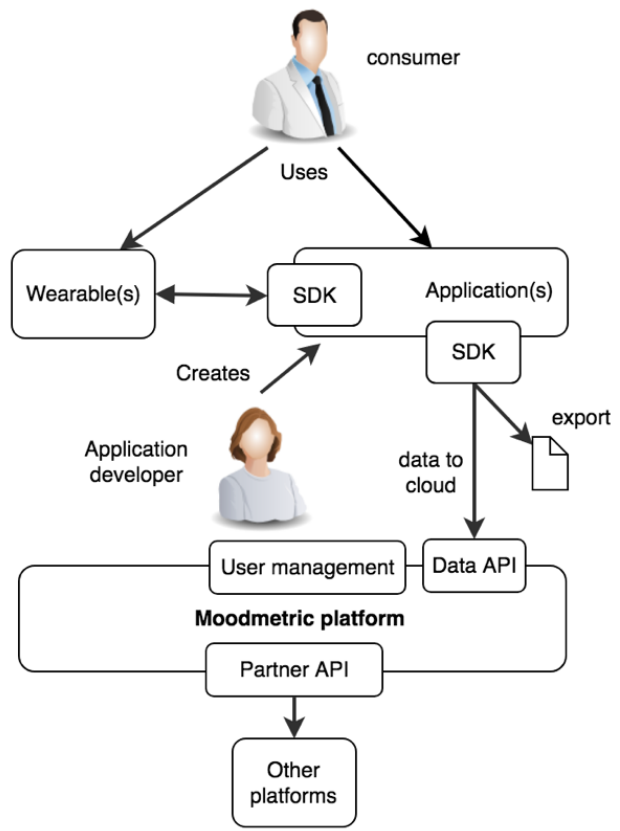

Figure 8: A vision for future Moodmetric platform.

One key driver of any ecosystem is an application developer community. Focus on Business to Developer (B2D) with product level tools such as an SDK would most likely lower the barrier to entry and boost ecosystem growth. The main purpose of any SDK is to make application development faster, easier, fun and more standardized. Thus, the SDK development should be application developer need driven. In other words, whatever feature application developers need and what makes their life easier, should be added to package.

Nascent Moodmetric platform currently provides partner API for data utilization by selected partners to build better services for various consumers. To enable easier data aggregation to cloud platforms, the SDK should provide ready-made API driven tools to connect data from wearables (the Moodmetric ring and all other wearables or sensors) to the selected mobile app or cloud, not only Moodmetric, with ease. This would create an end-to-end data management support in the SDK for the application developer. Data transfer functionality requires development of standard data model and API implemented by several cloud platforms. Without standard API, the SDK development might become cumbersome and complex since all platforms would have unique implementations. Some consumers want to use data in specific services. This requirement will be fulfilled by providing export function in SDK. Export data models should use and follow common de facto data models when possible. In addition, data formats should be open. 
One of the additional key services provided by the platform would be end-user identity and user management, which contains a login feature as well. Providing such services possibly via SDK or possibly directly via APIs would speed up application development and thus shorten time to market span. The SDK could contain ready-made login function for different platforms in the ecosystem and thus not tie all application development only to Moodmetric.

Providing just an SDK for developers is normally not enough. Access to offered application development tools and support should be one stop shop for application developers. Offering a simple developer portal with code and use case examples, SDK, documentation would be the beginning of developer program, which is needed in B2D marketing.

Emerging platforms of EDA applications might have different ways of working, e.g. different revenue models (such as subscription, license, freemium, or pay-as-you-go) [14] and they might be targeting a niche audience. When more such platforms emerge, data providers and users can choose a platform best fitting their needs, based on available data and platform regulation. To conclude, more cooperation between data providers, hardware (sensors, wearables) vendors and application developers is needed to enhance open data and API Economy.

\section{REFERENCES}

[1] Argyle, N. 1991. Skin Conductance Levels in Panic Disorder and Depression. The Journal of Nervous and Mental Disease. 179, 9 (Sep. 1991), 563-566. DOI:https://doi.org/10.1097/00005053-19910900000008 .

[2] Betella, A., Zucca, R., Cetnarski, R., Greco, A., Lanat Ã , A., Mazzei, D., Tognetti, A., Arsiwalla, X.D., Omedas, P., De Rossi, D. and Verschure, P.F.M.J. 2014. Inference of human affective states from psychophysiological measurements extracted under ecologically valid conditions. Frontiers in Neuroscience. 8, (Sep. 2014), 286. DOI:https://doi.org/10.3389/fnins.2014.00286.

[3] Bianco, V.D., Myllarniemi, V., Komssi, M. and Raatikainen, M. 2014 Bianco, V.D., Myllarniemi, V., Komssi, M. and Raatikainen, M. 2014.
The Role of Platform Boundary Resources in Software Ecosystems: A The Role of Platform Boundary Resources in Software Ecosystems: A
Case Study. 2014 IEEE/IFIP Conference on Software Architecture (Apr. 2014), 11-20.

[4] Biørn-Hansen, A., Majchrzak, T.A. and Grønli, T.-M. 2018. Progressive Web Apps for the Unified Development of Mobile Applications. Springer, Cham. 64-86.

[5] Blechert, J., Michael, T., Grossman, P., Lajtman, M. and Wilhelm, F.H. 2007. Autonomic and Respiratory Characteristics of Posttraumatic Stress 2007. Autonomic and Respiratory Characteristics of Posttraumatic Stress
Disorder and Panic Disorder. Psychosomatic Medicine. 69, 9 (Nov. 2007), 935-943. DOI:https://doi.org/10.1097/PSY.0b013e31815a8f6b. Boucsein, W. 2012. Electrodermal Activity. Springer US

[7] Braune, S., Albus, M., Fröhler, M., Höhn, T. and Scheibe, G. 1994. Psychophysiological and biochemical changes in patients with panic attacks in a defined situational arousal. European Archives of Psychiatry attacks in a defined situational arousal. European Archives of Psychiatry
and Clinical Neuroscience. 244, 2 (Aug. 1994), 86-92. DOI:https://doi.org/10.1007/BF02193524.

[8] Cowley, B., Filetti, M., Lukander, K., Torniainen, J., Henelius, A., Ahonen, L., Barral, O., Kosunen, I., Valtonen, T., Huotilainen, M., Ravaja, N. and Jacucci, G. 2016. The Psychophysiology Primer: A Guide to Methods and a Broad Review with a Focus on Human-Computer Interaction. Foundations and Trends $\mathbb{R}$ in Human-Computer Interaction. 9, 3-4 (2016), 151-308. DOI:https://doi.org/10.1561/1100000065.

[9] Critchley, H.D. 2002. Review: Electrodermal Responses: What Happens in the Brain. The Neuroscientist. 8, 2 (Apr. 2002), 132-142. DOI:https://doi.org/10.1177/107385840200800209.

[10] De, B. 2017. API Management. API Management. Apress. 15-28.

[11] Dolu, N., Süer, C., Özesmi, C., Kelestimur, F. and Esel, E. 1997. Electrodermal Activity in Nonmedicated Hyperthyroid Patients Having No Depressive Symptoms. Biological Psychiatry. 42, 11 (Dec. 1997),
1024-1029. DOI:https://doi.org/10.1016/S0006-3223(96)00551-3.

[12] Dolu, N., Süer, C. Özesmi, C., Kelestimur, F and Özcan, Y. 1999. Electrodermal Activity in Hypothyroid Patients and Healthy Subjects. Electrodermal Activit $\begin{array}{llll}\text { Thyroid } & 9, & 8 & \text { (Aug }\end{array}$ DOI:https://doi.org/10.1089/thy.1999.9.787.

[13] Dunderfelt, T. 2017. Valoisaksi. Viisas Elämä.

[14] Evans, P.C. and Basole, R.C. 2016. Revealing the API ecosystem and enterprise strategy via visual analytics. Communications of the ACM. 59 , 2 (Jan. 2016), 26-28. DOI:https://doi.org/10.1145/2856447.

[15] Förger, K. Himberg, T. Laroche, J. and Bachrach, A. 2018. FSenSync A software for enabling collaboration between art and science. Hybrid Labs Symposium 2018 (2018), 1.

[16] Garbarino, M., Lai, M., Bender, D., Picard, R., Tognetti, S. and 2014 undefined 2014. Empatica E3-A wearable wireless multi-sensor device for real-time computerized biofeedback and data acquisition. Wireless Mobile Communication and Healthcare (Mobihealth) (2014), 39-42.

[17] Grossman, P., Niemann, L., ... S.S.-J. of psychosomatic and 2004, U. 2004. Mindfulness-based stress reduction and health benefits: A metaanalysis. Journal of psychosomatic research. 57, 1 (2004), 35-34.

[18] Hartig, T., Mitchell, R., de Vries, S. and Frumkin, H. 2014. Nature and Health. Annual Review of Public Health. 35, 1 (Mar. 2014), 207-228. DOI:https://doi.org/10.1146/annurev-publhealth-032013-182443.

[19] Hoehn, T., Braune, S., Scheibe, G. and Albus, M. 1997. Physiological, biochemical and subjective parameters in anxiety patients with panic disorder during stress exposure as compared with healthy controls. disorder during stress exposure as compared with healthy controls.
European Archives of Psychiatry and Clinical Neuroscience. 247,5 (Oct. European Archives of Psychiatry and Clinical Neuroscience.

[20] Iansiti, M. and Levien, R. 2004. Strategy as ecology. Harvard busines review. 82, 3 (Mar. 2004), 68-78, 126

[21] Ilvonen, I., Jussila, J., Karkkainen, H. and Paivarinta, T. 2015. Knowledge Security Risk Management in Contemporary Companies Toward a Proactive Approach 2015 48th Hawaii International Conference on System Sciences (Jan. 2015), 3941-3950.

[22] Kabat-Zinn, J. 2003. Mindfulness-based stress reduction. Constructivism in the Human Sciences. 8, 2 (2003), 73-107.

[23] Kappeler-Setz, C., Gravenhorst, F., Schumm, J., Arnrich, B. and Tröster, G. 2013. Towards long term monitoring of electrodermal activity in daily life. Personal and Ubiquitous Computing. 17, 2 (Feb. 2013), 261-271. DOI:https://doi.org/10.1007/s00779-011-0463-4.

[24] Kenney, M. and Zysman, J. 2016. The rise of the platform economy. Kenney, M. and Zysman, J. 2016. The rise of the p.
Issues in Science and Technology. 32, 3 (2016), 61-69.

[25] Lader, M.H. and Wing, L. 1964. Habituation of the psycho-galvanic reflex in patients with anxiety states and in normal subjects. Journal of neurology, neurosurgery, and psychiatry. 27, 3 (Jun. 1964), 210-8.

[26] Lee, Y., Yoon, S., Lee, C. and Lee MH 2006. Wearable EDA senso gloves using conducting fabric and embedded system. EMBS'06. 28th Annual International Conference of the IEEE (2006), 6785-6788.

[27] Moilanen, J., Niinioja, M., Seppänen, M. and Honkanen, M. 2018. APItalous 101. Alma Talent Oy.

[28] Moore, J.F. 1993. Predators and prey: a new ecology of competition. Harvard business review. 71, 3 (1993), 75-86.

[29] Pantelopoulos, A and Bourbakis, N.G. 2010. A Survey on Wearable Sensor-Based Systems for Health Monitoring and Prognosis. IEEE Transactions on Systems, Man, and Cybernetics, Part C (Applications Transactions on Systems, Man, and Cybernetics, Part C (Applications
and Reviews). 40, 1 (Jan. 2010), 1-12. $\begin{array}{llccc}\text { and Reviews). 40, } & 1 & \text { (Jan. } \\ \text { DOI:https://doi.org/10.1109/TSMCC.2009.2032660. }\end{array}$

[30] Picard, R., Migliorini, M., Caborni, C., Onorati, F., Regalia, G., Friedman, D. and Devinsky, O. 2017. Wrist sensor reveals sympathetic hyperactivity and hypoventilation before probable SUDEP. Neurology. 89, 6 (2017), 633-635.

[31] Poh, M. Swenson, N. and Picard, R. 2010. A wearable sensor fo Poh, M., Swenson, N. and Picard, R. 2010. A wearable sensor for
unobtrusive, long-term assessment of electrodermal activity. IEEE transactions on Biomedical engineering. 57, 5 (2010), 1243-1252.

[32] Sandifer, P.A., Sutton-Grier, A.E. and Ward, B.P. 2015. Exploring connections among nature, biodiversity, ecosystem services, and human health and well-being: Opportunities to enhance health and biodiversity conservation. Ecosystem Services. 12, (Apr. 2015), 1-15. DOI:https://doi.org/10.1016/J.ECOSER.2014.12.007.

[33] Sarén, H. and Uosukainen, L. 2016. Luonnon hyvinvointivaikutukset ja hyvinvointiteknologia matkailun näkökulmasta.

[34] Setz, C., Arnrich, B., Schumm, J., La Marca, R., Tröster, G. and Ehlert, U. 2010. Discriminating stress from cognitive load using a wearable EDA device. IEEE Transactions on information technology in biomedicine. 14 2 (2010), 410-417.

[35] Suoja, K., Liukkonen, J., Jussila, J., Salonius, H., Venho, N., Sillanpää, V., Vuori, V. and Helander, N. 2018. Application for pre-processing and visualization of electrodermal activity wearable data. EMBEC \& NBC 2017 (2018), 93-96. 
Towards ecosystem for research and development of electrodermal activity applications

Mindtrek 2018, October 10-11, 2018, Tampere, Finland

[36] Suomalainen fitness-sovellus on paljastanut satojen sotilaiden liikkeitä | Long Play: 2018. https://www.longplay.fi/sivuäänet/suomalainen-fitnesssovellus-paljastanut-satojen-sotilaiden-liikkeita. Accessed: 2018-07-08.

[37] Suominen, A.H., Jussila, J., Lundell, T., Mikkola, M. and AramoImmonen, H. 2018. Educational Hackathon: Innovation Contest for Innovation Pedagogy. The ISPIM Innovation Conference - Innovation, Innovation Pedagogy. The ISPIM Innovation Conference -
The Name of The Game, 17-20 June 2018. (Stockholm, 2018).

[38] Thomas, L. and Autio, E. 2012. Modeling the ecosystem: a metasynthesis of ecosystem and related literatures. DRUID 2012 Conference (Copenhagen, 2012).

[39] Torniainen, J., Cowley, B., Henelius, A., Lukander, K. and Pakarinen, S. 2015. Feasibility of an electrodermal activity ring prototype as a research tool 201537 th Annual International Conference of the IEEE Engineering in Medicine and Biology Society (EMBC) (Aug. 2015), Engineering in Medicine and Biology Society (EMBC) (Aug. 2015),
$6433-6436$.

[40] Vardasca, R.Â.R. 2011. The effect of work related mechanical stress on the peripheral temperature of the hand. University of Glamorgan.

[41] Vukovic, M., Srivastava, B., Branch, J.W., Laredo, J., Muthusamy, V., Slominski, A., Vaculin, R., Tan, W., Naik, V., Silva-Lepe, I. and Kumar, A. 2016. Riding and thriving on the API hype cycle. Communications of
the ACM. 59, 3 (Feb. 2016), 35-37. DOI:https://doi.org/10.1145/2816812

[42] Ward, N.G., Doerr, H.O. and Storrie, M.C. 1983. Skin conductance: A potentially sensitive test for depression. Psychiatry Research. 10, 4 (Dec. 1983), 295-302. DOI:https://doi.org/10.1016/0165-1781(83)90076-8.

[43] Yin, R. 2003. Case study research and applications: Design and methods. SAGE.

[44] Yin, R.K. 2011. Applications of case study research. SAGE. 